\title{
Annotation
}

Archives of Disease in Childhood, 1973, 48, 663.

\section{Beclomethasone in childhood asthma}

It has not been possible so far to produce a systemic corticosteroid with anti-inflammatory effect on local tissues and without glucocorticoid action. However, esterification of the potent antiinflammatory steroid betamethasone with valeric acid in the 17 carbon position produced betamethasone-17-valerate (Betnovate ${ }^{\star}$ ), a steroid with marked topical anti-inflammatory activity. Beclomethasone dipropionate, a chlorinated analogue of betamethasone esterified with propionic acid, has greater topical anti-inflammatory activity and has been marketed for dermatological use as Propaderm. A pressurized aerosol containing beclomethasone (Becotide $f$ ) is now undergoing clinical trials, of which two are reported on pages 665 and 671 of this issue, in the hope that the margin of difference between the high local topical activity and the systemic glucocorticoid effects will be greater than can be achieved with other steroids whether given orally, systemically, or by inhalation. That there is a differential effect of this kind has not yet been definitely established. There has been no experimental animal evidence so far, despite high and prolonged dosage, to suggest any toxic action on the lung (D. Poynter, personal communication, 1973). The drug is cleared from the lung within an hour, whereas it persists in the skin much longer (D. M. Harris, personal communication, 1973). A large proportion of the inhaled dose is deposited in the mouth and pharynx and is swallowed (Blackwell et al., 1970). Absorption from the alimentary tract is rapid, the drug appearing in the plasma 5 minutes after swallowing a microfine suspension. These authors also showed that a micronized suspension after inhalation is almost completely absorbed via the gut and perhaps also the lung, and subsequently is slowly excreted in the urine and bile.

Evidence is accumulating that daily inhalations in excess of $1 \mathrm{mg}$ cause sufficient systemic absorption to depress hypothalamic-pituitary-adrenal function in normals (Harris et al., 1973) and asthmatics (Choo-Kang et al., 1972). The drug is inhaled from a metered aerosol delivering $50 \mu \mathrm{g}$ per dose, and the usual dose is 300 to $600 \mu \mathrm{g}$ per day. Reports

* Glaxo Laboratories Ltd.

tAllen and Hanbury Ltd. suggest that this dose level seems to avoid systemic effects and achieves reasonable control in the adult (Clark, 1972; Lal et al., 1972; Chatterjee, et al. 1972; Morrow Brown, Storey, and George, 1972), and the reports from Godfrey and König (1973) and from Dickson et al. (1973) in children outline similar experience. The effect which can be achieved by this dose, however, is approximately that comparable with $5 \mathrm{mg}$ prednisolone by mouth, and, as would be expected, the evidence at present indicates that this will not control all severe asthmatic children so that the drug may have to be combined with ACTH or be used in higher dosage, in which case careful clinical and biochemical monitoring for side effects is necessary.

Certain practical considerations are of paramount importance. When there is failure of response the technique of inhalation should be examined carefully as it may well be defective, especially in the younger child. It is essential for the patient or parent to appreciate that the drug, like disodium cromoglycate, is a preventive agent which must be taken regularly and is not suitable for the treatment of an attack. Indeed, the patient may be at risk if a severe attack of asthma or a respiratory infection should occur because he may not be able to inhale the drug or it may fail to reach the bronchioles. Therefore, it is essential to ensure adequate steroid cover by oral or systemic routes at these times. This applies especially if the patient has been on maintenance oral steroid previously. When changing from oral steroid to beclomethasone, it should not be assumed that because one is substituting one steroid for another it can be done more or less abruptly. The oral steroid should be tailed off slowly in the usual fashion, otherwise the patient may be exposed to grave risk if a severe infection should occur. With the addition of this important drug to our armamentarium, the longterm treatment of children with oral steroid is no longer desirable because better alternatives are now available.

R. S. JONES

The Institute of Child Health and Alder Hey Children's Hospital, Eaton Road, Liverpool L12 2AP. 


\section{REFERENCES}

Blackwell, E. W., Connolly, M. E., Davies, D. S., and Dollery, C. T. (1970). The fate of isoprenaline administered by pressurized aerosols. British fournal of Pharmacology, 39, 194P.

Chatterjee, S. S., Ross, A. E., Carroll, K., Harris, D. M., and Butler, A. G. (1972). Respiratory function on asthmatic patients using beclomethasone dipropionate administered by pressurised aerosol. Current Medical Research and Opinion, 1, No. 3, 173.

Choo-Kang, Y. F. J., Cooper, E. J., Tribe, A. E., and Grant, I. W. B. (1972). Beclomethasone dipropionate by inhalation in the treatment of airways obstruction. British fournal of Diseases of the Chest, 66, 101.

Clark, T. J. H. (1972). Effect of beclomethasone dipropionate delivered by aerosol in patients with asthma. Lancet, 1, 1361.
Dickson, W., Hall, C. E., Ellis, M., and Horrocks, R. H. (1973). Beclomethasone dipropionate aerosol in childhood asthma. Archives of Disease in Childhood, 48, 671.

Godfrey, S., and König, P. (1973). Beclomethasone aerosol in childhood asthma. Archives of Disease in Childhood, 48, 665.

Harris, D. M., Martin, L. E., Harrison, C., and Jack, D. (1973) The effect of oral and inhaled beclomethasone dipropionate on adrenal function. Clinical Allergy. (In the press.)

Lal, S., Harris, D. M., Bhalla, K. K., Singhal, S. N., and Butler. A. G. (1972). Comparison of beclomethasone dipropionate aerosol and prednisolone in reversible airways obstruction. British Medical fournal, 3, 314.

Morrow Brown, H., Storey, G., and George, W. H. S. (1972). Beclomethasone dipropionate: a new steroid aerosol for the treatment of allergic asthma. British Medical fournal, 1, 585. 